\title{
Incidence of chronic myeloid leukemia and patient survival: results of five French population-based cancer registries 1980-2009
}

\author{
Amélie Penot ${ }^{1}$, Pierre-Marie Preux ${ }^{2}$, Sandra Le Guyader ${ }^{3}$, Albert Collignon ${ }^{4}$, Aurélie Herry ${ }^{5}$, Vinciane Dufour ${ }^{6}$, \\ Alain Monnereau ${ }^{3}$, Anne-Sophie Woronoff ${ }^{6}$, Xavier Troussard ${ }^{4}$, Elisabeth Pons ${ }^{7}$, Dominique Bordessoule ${ }^{1}$ \\ \& Marc Maynadié5,8 \\ ${ }^{1}$ Service d'hématologie et de thérapie cellulaire, $\mathrm{CHU}$ de Limoges, France, ${ }^{2}$ Unité fonctionnelle de recherche clinique et de \\ biostatistiques, UMR INSERM1094, CHU de Limoges, France, ${ }^{3}$ Registre des hémopathies malignes de Gironde, Institut Bergonié, \\ Bordeaux, France, ${ }^{4}$ Registre régional des hémopathies de Basse-Normandie, Caen, France, ${ }^{5}$ Registre des hémopathies \\ malignes de Côte d'Or, Université de Bourgogne, France, ${ }^{6}$ Registre des tumeurs du Doubs, CHU de Besançon, France, \\ ${ }^{7}$ Registre général des cancers en région Limousin, $\mathrm{CHU}$ de Limoges, France and ${ }^{8}$ Laboratoire d'hématologie biologique, \\ EA 4184, CHU de Dijon, France
}

\begin{abstract}
The treatment of chronic myeloid leukemia (CML) has seen several major advances over the past 30 years, notably with the introduction of interferon followed by $\mathrm{Bcr}-\mathrm{Abl}$ tyrosine kinase inhibitors. We analyzed trends in the incidence of CML and patient survival in France. All cases recorded in five populationbased registries between 1980 and 2009 were included. European (ESR) and world (WSR) standardized incidence rates as well as relative survival (RS) rates were estimated. We analyzed data for 781 patients (9863/3: 13.6\%; 9875/3: 82.2\%; 9876/3: 4.2\%). ESR was 1.02 [95\% confidence interval $(\mathrm{Cl})=0.93-1.11]$ and WSR was $0.81[95 \% \mathrm{Cl}=0.72-0.90]$. The five $\mathrm{RS}$ rates among patients with Philadelphia chromosome positive $(\mathrm{Ph}+) \mathrm{CML}$ were $43.7 \%$ [30.9-61.9] when diagnosed in 1980-1986, 63.8\% [56.9-71.5] in 1987-1999 and 88.7\% [84.5-93.0] in 2000-2009. The 8-year $\mathrm{RS}$ rate of patients with $\mathrm{Ph}+\mathrm{CML}$ diagnosed in 2000-2009 was 83.3\% [77.5-89.4]. Therapeutic innovations have thus led to a significant increase in long-term survival in the general CML patient-population.
\end{abstract}

Keywords: Chronic myeloid leukemia, incidence, relative survival, population-based registries

\section{Introduction}

Successive advances in treatment and molecular monitoring of the therapeutic response have revolutionized the management and prognosis of chronic myeloid leukemia (CML). The first therapeutic target was identified 40 years after discovery of the Philadelphia $(\mathrm{Ph})$ chromosome (reciprocal translocation 9;22) [1], 25 years after the development of the first methods to quantify Ph-positive metaphases in bone marrow [2], and 15 years after the introduction of techniques for identifying and measuring BCR-ABL transcripts with deregulated tyrosine kinase activity [3]. The first tyrosine kinase inhibitor (TKI) was introduced in the early 2000s, along with therapeutic monitoring by means of real-time quantitative polymerase chain reaction (RQ-PCR). The prognosis of CML has thus been transformed, using oral medication.

In the 1990s, treatment options for newly diagnosed patients with CML consisted of bone marrow transplant (BMT), interferon alpha (IFN $\alpha$ ) and chemotherapy (busulfan, cytarabine) or hydroxyurea. Five-year survival rates were disappointing, at around $57 \%$ with IFN $\alpha$ and $42 \%$ with chemotherapy [4]; the probability of long-term survival was $50-80 \%$ among the $20-30 \%$ of patients eligible for allogenic BMT $[5,6]$. In 2001, the first phase I clinical trial [7] of imatimib mesylate (IM) showed cytogenetic responses in patients with unsatisfactory responses to standard treatments. IM became the first-line treatment for CML following the IRIS study (International Randomized Study of Interferon vs. STI571) [8], and was shown in 2004 to markedly enhance patient survival [9]. The second generation of TKIs (dastinib, nilotinib) seems to be even more effective than IM [10-12]. However, few data are available on the long-term survival of the general population of patients with CML treated with TKIs.

The aim of this study was to examine trends in the incidence of CML and patient survival in France over a 30 -year period. We conducted a retrospective cohort study of consecutive, unselected patients with CML registered in five French population-based cancer registries between 1980 and 2009.

\section{Patients and methods}

Data sources

Cases were identified with the participation of five French population-based registries that each exhaustively collect all

Correspondence: Amélie Penot, 2 avenue Martin Luther King, 87000 Limoges, France. Tel: 33(0)555056642. Fax: 33(0)555056649. E-mail:

amelie.penot@chu-limoges.fr 
cases of cancer within the relevant administrative area. The Côte-d'Or registry specializing in hematologic malignancies and the Doubs general cancer registry each represents a population of about 500000 inhabitants; the Limousin general cancer registry covers about 720000 inhabitants; and the Basse-Normandie and Gironde registries specializing in hematologic malignancies cover about 1440000 inhabitants each. Exhaustive data were available for 1980-2009 in the oldest registries (Côte-d'Or and Doubs), 1993-2009 in the Limousin registry, 1997-2008 in the Basse-Normandie registry and 2002-2008 in the Gironde registry.

\section{Patient selection}

All cases of CML registered between 1980 and 2009 were included. Before the publication of the third edition of the International Classification of Diseases for Oncology (ICD-O-3), a unique code (9863/3) was used for CML [13]. After publication of ICD-O-3 [14] in 2000, two supplementary codes were created: $9875 / 3(\mathrm{Ph}+\mathrm{CML}$ with positive genetic [reciprocal translocation 9;22] or molecular biology [Bcr-Abl chimeric protein] documentation) and 9876/3 (myeloproliferative syndrome described in ICD-O-3 as CML with negative genetic and molecular biology studies: $\mathrm{Ph}-\mathrm{CML}$ or atypical CML). The former code $9863 / 3$ was conserved from the previous edition of ICD-O. The ICD$\mathrm{O}-3$ classification has often been applied retrospectively to code cases before 2000 . We chose to include patients coded $9863 / 3$ in order to avoid underestimating the incidence of CML, but this code included both patients with Ph + CML and patients with $\mathrm{Ph}-\mathrm{CML}$. It was therefore necessary to study patients with $\mathrm{Ph}-\mathrm{CML}$ to understand the results for patients coded 9863/3.

\section{Statistical analysis}

Crude and age-standardized incidence rates and their confidence intervals were calculated according to Bouyer et al. [15] with data of french population [16]. All results are reported as the number of cases per 100000 inhabitants per year with $95 \%$ confidence intervals (CIs). We estimated incidence rates according to age at diagnosis (0-14, 15-44, 45-54,
55-64, 65-74 and 75-99 years). Age-standardized incidence rates were estimated using the direct method and calculated for reference populations: the Europe standard population (ESP) defined according to Waterhouse [17] and the World standard population (WSP) corresponding to Segi's world standards [18]. The cut-off date for determining vital status was 31 December 2013. Relative survival (RS) was defined as the ratio between observed survival and expected survival in the corresponding general population, thereby expressing the probability of CML survival after adjustment for competing causes of death. We used French mortality data published by the Human Mortality Database [19]. RS was calculated using the Maya Pohar-Perme method implemented with the relsurv package for R [20]. All analyses were performed with R 3.0.2 open access software.

\section{Results}

\section{Study population}

Between 1 January 1980 and 31 December 2009, 781 new diagnoses of CML were registered. The characteristics of the study population are shown in Table I according to the period of diagnosis.

Mean age at diagnosis was 57.4 years $( \pm 16.7)$. The male/ female sex ratio was 1.36 . Patients classified as $9875 / 3$ represented $82.2 \%$ of the cohort. Only $13.6 \%$ of patients overall were classified as 9863/3 (CML-not otherwise specified [NOS]), and the proportion of these patients fell with time, from $22 \%$ in $1980-1986$ to $17 \%$ in $1987-1999$ and $11 \%$ in $2000-2009$. The proportion of patients classified as $9876 / 3$ was $4.2 \%$, and this population had different sociodemographic characteristics from the rest of the cohort, particularly a higher mean age (71.8 vs. 56.7 years, $p<0.0001$ ). The estimated mean incidence of patients with CML in metropolitan France was 751 cases per year $( \pm 92)$.

\section{Incidence}

The crude incidence rate was 1.14 [1.14-1.14] per 100000 person-years overall, 1.31 [1.31-1.13] in men and 0.98 [0.98-0.98] in women.

Table I. Characteristics of study cohort of 781 chronic myeloid leukemia patients.

\begin{tabular}{|c|c|c|c|c|}
\hline & \multicolumn{4}{|c|}{ Period of diagnosis } \\
\hline & $\begin{array}{c}1980-1986 \\
(n=69)\end{array}$ & $\begin{array}{c}1987-1999 \\
(n=250)\end{array}$ & $\begin{array}{c}2000-2009 \\
(n=462)\end{array}$ & $\begin{array}{c}\text { Total } \\
(n=781)\end{array}$ \\
\hline \multicolumn{5}{|c|}{ Age class at diagnosis, years, $(n, \%)$} \\
\hline $0-14$ & $1(1)$ & $5(2)$ & $2(0)$ & $8(1)$ \\
\hline $15-44$ & $23(33)$ & $59(24)$ & 90 (19) & $172(22)$ \\
\hline $45-54$ & 7 (10) & 44 (18) & $85(18)$ & $136(18)$ \\
\hline $55-64$ & $14(20)$ & $62(25)$ & $89(19)$ & $165(21)$ \\
\hline $65-74$ & $15(22)$ & 47 (19) & $111(24)$ & $173(22)$ \\
\hline $75-99$ & $9(13)$ & 33 (13) & $85(18)$ & $127(16)$ \\
\hline Mean (SD) & $54.3(18.5)$ & $55.8(16.4)$ & $58.7(16.5)$ & $57.4(16.7)$ \\
\hline \multicolumn{5}{|l|}{$\operatorname{Sex}(n, \%)$} \\
\hline Men & $43(62)$ & $139(56)$ & $258(56)$ & $440(56)$ \\
\hline Women & $26(38)$ & $111(44)$ & $204(44)$ & $341(44)$ \\
\hline \multicolumn{5}{|l|}{ ICD-O-3 code $(n, \%)$} \\
\hline 9875/3: Ph+_CML & $48(70)$ & $201(80)$ & $393(85)$ & $642(82)$ \\
\hline 9863/3: CML_NOS & $15(22)$ & $42(17)$ & $49(11)$ & $106(14)$ \\
\hline 9876/3: uMDS/MPS & $6(9)$ & $7(3)$ & $20(4)$ & $33(4)$ \\
\hline
\end{tabular}


Table II. Age-standardized incidence for 100000 person-years during 1990-2009.

\begin{tabular}{lcc}
\hline & ESR [95\% CI] & WSR [95\% CI] \\
\hline $\mathrm{Ph}+$ _CML & & \\
Men & $1.12[0.99-1.24]$ & $1.09[0.96-1.22]$ \\
Women & $0.85[0.74-0.95]$ & $0.74[0.63-0.84]$ \\
All & $0.97[0.88-1.05]$ & $0.78[0.71-0.85]$ \\
$\mathrm{Ph}+$ CCML \& CML_NOS & & \\
Men & $1.27[1.14-1.41]$ & $1.25[1.11-1.39]$ \\
Women & $0.96[0.86-1.08]$ & $0.83[0.72-0.93]$ \\
All & $1.10[1.01-1.19]$ & $0.89[0.81-0.96]$ \\
\hline
\end{tabular}

ESR, European standardized ratio, WSR: World standardized ratio.

Crude incidence rates ranged from 0.07 per 100000 person-years in the age group $0-14$ years to 0.60 at $15-44$ years, 1.49 at $45-54$ years, 2.29 at $55-64$ years, 2.79 at $65-74$ years and 2.34 at $75-99$ years.

The crude incidence rates among patients with CML $9875 / 3$ were 0.05 at $0-14$ years, 0.55 at $15-44$ years, 1.36 at $45-54$ years, 1.97 at $55-64$ years, 2.28 at $65-74$ years and 1.58 at $75-99$ years.

The age-standardized incidence rate of cohort and $\mathrm{Ph}+\mathrm{CML}$ was respectively $1.02[0.93-1.11]$ and $0.97[0.88-$ 1.05] relative to the European standardized rate (ESR), and $0.81[0.72-0.90]$ and $0.78[0.71-0.85]$ relative to the world standardized rate (WSR). Age-standardized incidence rates are reported in Table II.

\section{Treatments}

The treatments received were available for 679 patients. Table III describes the treatments in three calendar periods of diagnosis.

As shown in Table III, most patients diagnosed as $9875 / 3$ in 1980-1986 received chemotherapy (hydroxyurea or other). New treatments such as IFN $\alpha$ and autologous stem cell transplant were used in 1987-1999. Only a few patients (mainly young patients with matched donors) received BMT. Among the patients diagnosed in 2000-2009, 96.3\% received a TKI. Some long-term survivors diagnosed earlier also received a TKI: $4 \%$ of patients diagnosed in 1980-1986 and $29 \%$ of patients diagnosed in 1987-1999.

Patients with CML-NOS diagnosed in 1980-1986 received chemotherapy (33.3\%), BMT (33.3\%) and/or hydroxyurea (66.7\%), alone, in combination or sequentially. In 19871999, hydroxyurea and BMT were the most frequently prescribed treatments, but more than $29.4 \%$ of these patients subsequently received a TKI. Among patients diagnosed in 2000-2009, 93.3\% were prescribed a TKI.

Patients with $\mathrm{Ph}-\mathrm{CML}$ diagnosed in 1980-1986 received chemotherapy (50.0\%) or hydroxyurea (50.0\%). In 2000-2009, TKIs were prescribed to $29.4 \%$ of these patients.

\section{Relative survival}

Median follow-up was 51 months. The 5-year RS rate among patients diagnosed in 1980-1986, before the use of IFN $\alpha$, was only $40.2 \%$ [28.7-56.4]. This rate improved to $59.4 \%$ [53.0-66.5] for patients diagnosed in 1987-1999 and to 82.6\% [78.3-87.1] in the TKI era. The 5-year RS rate was 77.4\% [73.6-81.3] among patients diagnosed with $\mathrm{Ph}+\mathrm{CML}$ in 1980-2009, 52.8\% [42.2-66.0] in patients with CML-NOS and 12.1\% [4.6-32.1] in patients with $\mathrm{Ph}-\mathrm{CML}$. Figure 1 shows RS rates according to ICD-O-3 code and calendar period of diagnosis.

Among patients with $\mathrm{Ph}+\mathrm{CML}(n=642)$, the median RS time was 48 months for those diagnosed in 1980-1986, 90 months in 1987-1999 and not reached in 2000-2009. The 5- and 8-year RS rates were respectively 43.7\% [30.9-61.9]

Table III. Treatments received during follow-up according to period of diagnosis and ICD-O-3 codes $(n=679)$.

\begin{tabular}{|c|c|c|c|c|c|}
\hline \multirow[b]{2}{*}{ Morphologic type } & \multicolumn{5}{|c|}{ Period of diagnosis } \\
\hline & $\begin{array}{l}\text { Treatments received } \\
\text { during follow-up }\end{array}$ & $\begin{array}{c}1980-1986 \\
(n=57)\end{array}$ & $\begin{array}{c}1987-1999 \\
(n=199)\end{array}$ & $\begin{array}{l}2000-2009 \\
(n=423)\end{array}$ & Total \\
\hline \multicolumn{6}{|c|}{ 9875/3 Ph+_CML, $n(\%)$} \\
\hline & BMT & $3(6)$ & $13(7)$ & $8(2)$ & $24(4)$ \\
\hline & Chemotherapy & $25(53)$ & $13(7)$ & $4(11)$ & $42(7)$ \\
\hline & Hydroxyurea & $38(81)$ & $140(79)$ & $62(17)$ & $240(40)$ \\
\hline & IFN $\alpha$ & $3(6)$ & $113(64)$ & $33(9)$ & $149(25)$ \\
\hline & ASCT & $2(4)$ & $31(18)$ & $3(1)$ & $36(6)$ \\
\hline & TKI & $2(4)$ & $52(29)$ & $362(96)$ & $416(69)$ \\
\hline & Total & 47 & 177 & 376 & 600 \\
\hline \multicolumn{6}{|c|}{ 9863/3 CML-NOS, $n(\%)$} \\
\hline & BMT & $2(33)$ & $5(29)$ & $2(10)$ & $9(17)$ \\
\hline & Chemotherapy & $2(33)$ & 0 & 0 & $2(4)$ \\
\hline & Hydroxyurea & $4(66)$ & $8(47)$ & $3(7)$ & $15(28)$ \\
\hline & IFN $\alpha$ & 0 & $3(18)$ & 0 & $3(6)$ \\
\hline & ASCT & 0 & 0 & 0 & 0 \\
\hline & TKI & 0 & $7(41)$ & $28(93)$ & $35(66)$ \\
\hline & Total & 6 & 17 & 30 & 53 \\
\hline \multicolumn{6}{|c|}{ 9876/3 atypical CML, $n(\%)$} \\
\hline & BMT & 0 & 0 & 0 & 0 \\
\hline & Chemotherapy & $2(50)$ & 0 & 0 & $2(8)$ \\
\hline & Hydroxyurea & $2(50)$ & $5(100)$ & $11(65)$ & $18(70)$ \\
\hline & IFN $\alpha$ & 0 & 0 & 0 & 0 \\
\hline & ASCT & 0 & 0 & 0 & 0 \\
\hline & TKI & 0 & 0 & $5(29)$ & $5(19)$ \\
\hline & Total & 4 & 5 & 17 & 26 \\
\hline
\end{tabular}

Ph+_CML: Philadelphia chromosome-positive chronic myeloid leukemia; CML_NOS: chronic myeloid leukemia not otherwise specified; atypical CML: atypical chronic myeloid leukemia; BMT: bone marrow transplantation; IFN $\alpha$ : interferon alpha; ASCT: autologous stem-cell transplant; TKI: tyrosine kinase inhibitor. 

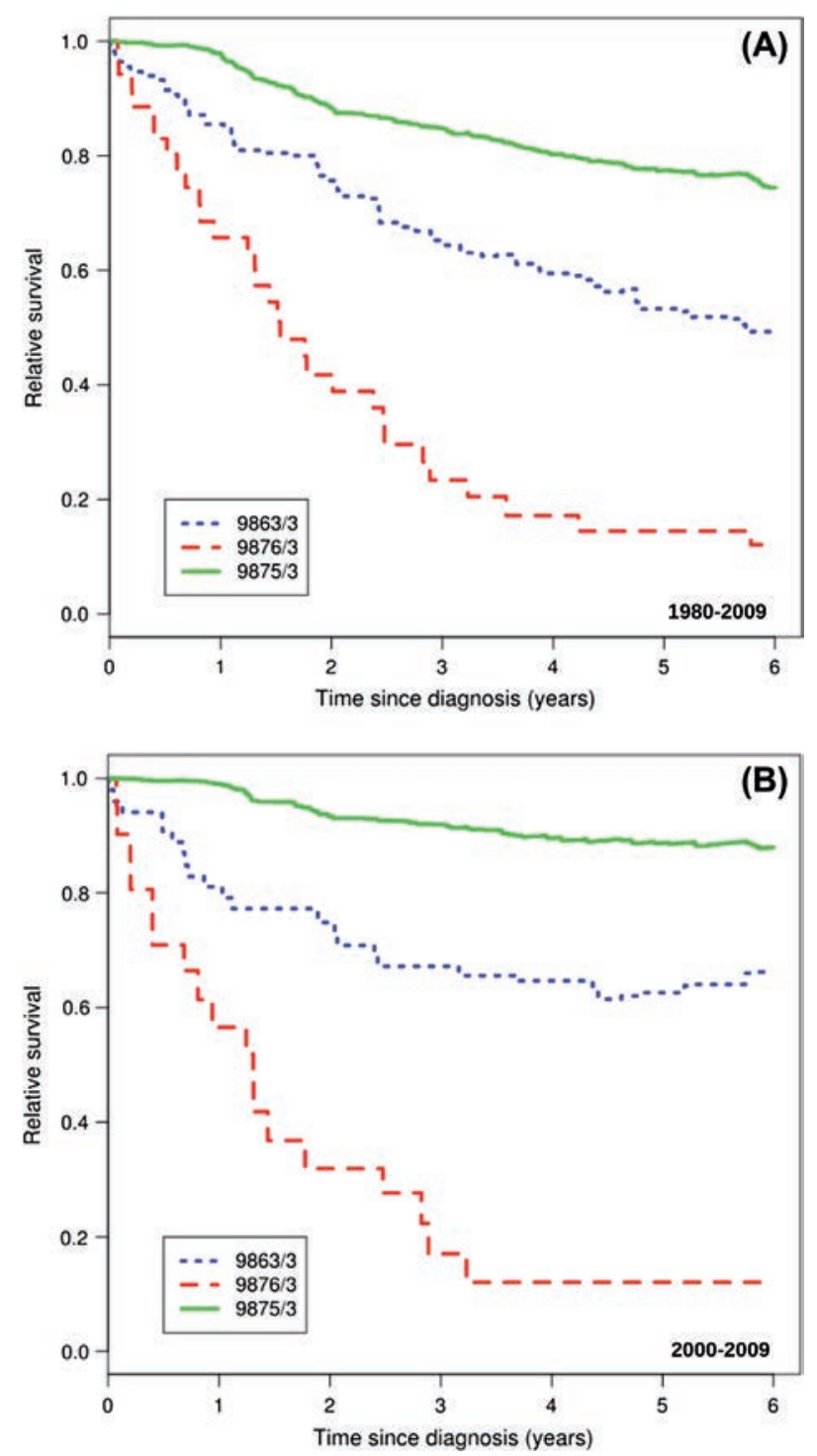

Figure 1. (A) Relative survival of patients diagnosed in 1986-2009 according to ICD-O-3 code. (B) Relative survival of patients diagnosed in 1980-2009 according to ICD-O-3 code.

and $30.6 \%$ [19.2-48.8] for patients diagnosed in 1980-1986, 63.8\% [56.9-71.5] and 47.0\% [39.9-55.5] in 1987-1999 and 88.7\% [84.5-93.0] and 73.3\% [77.5-89.4] in 2000-2009. The 8-year RS rate among patients with $\mathrm{Ph}+\mathrm{CML}$ aged less than 65 years increased across the three periods, from $38.4 \%$ [25.5-57.6] in 1980-1986 to 50.4\% [42.6-59.7] in 1987-1999 and $89.7 \%$ [84.7-94.9] in 2000-2009. The 8-year RS rate among patients diagnosed with $\mathrm{Ph}+\mathrm{CML}$ at age 65 years or more also increased, from $0 \%$ in $1980-1986$ to $40.1 \%$ [26.9-59.9] in 1987-1999 and 73.7\% [62.6-86.8] in 2000-2009.

Five- and 8-year RS rates among patients with $\mathrm{Ph}+\mathrm{CML}$ aged $45-64$ years were respectively $48.6 \%$ [35.0-67.6] and $38.4 \%$ [25.5-57.6] for those diagnosed in 1980-1986, $62.4 \%$ [54.7-71.1] and 50.4\% [42.6-59.7] in 1987-1999 and 92.0\% [88.2-95.9] and $89.7 \%$ [84.7-94.9] in 2000-2009. Figure 2 shows RS curves for patients with $\mathrm{Ph}+\mathrm{CML}$.

Likewise, the 5- and 8-year RS rates among patients with $\mathrm{Ph}+\mathrm{CML}$ aged 65 years or more improved from respectively $26.7 \%$ [8.3-86.0] and $1.4 \%$ [0.1-17.6] for patients diagnosed
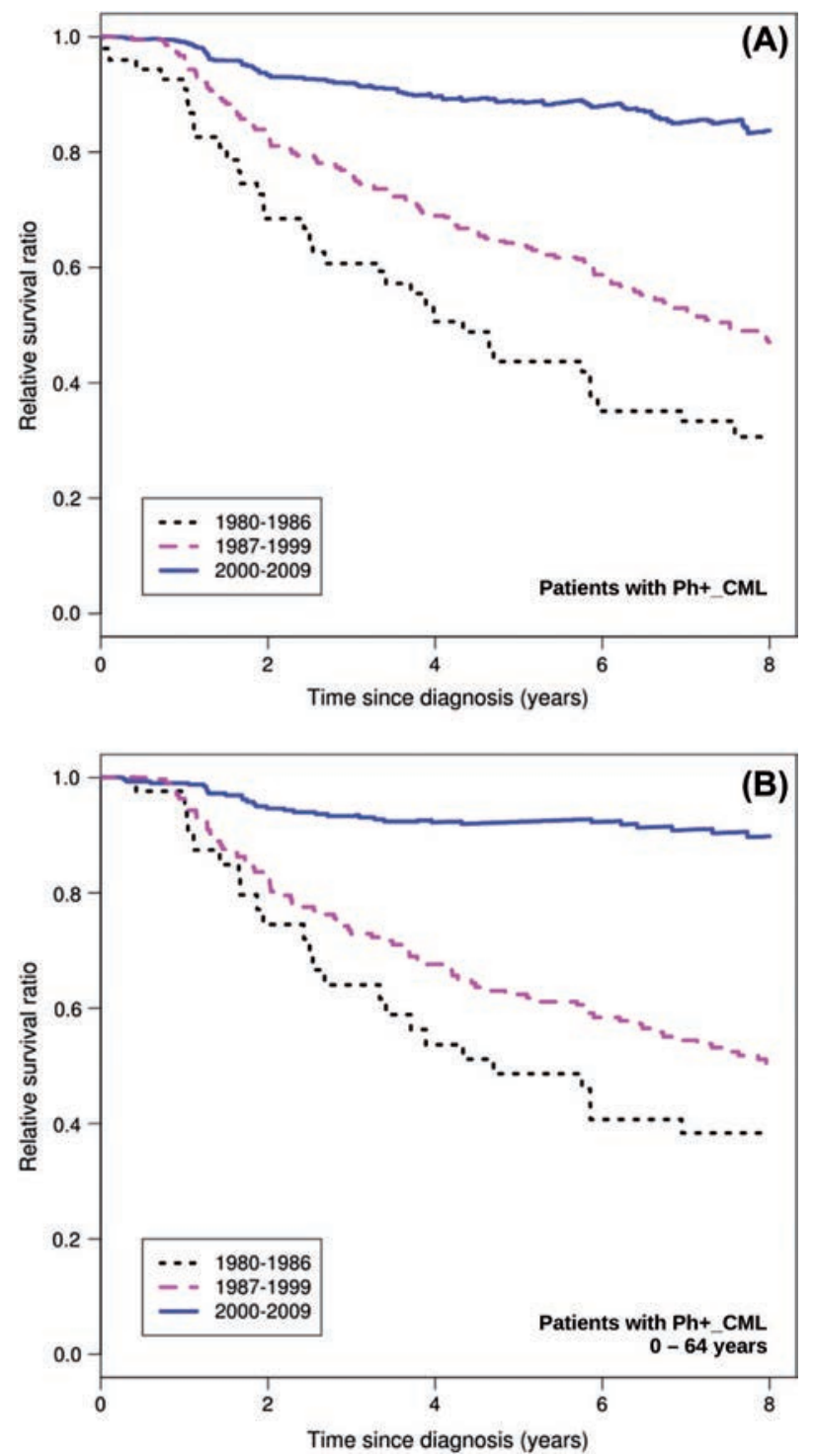

Figure 2. (A) Relative survival of patients with $\mathrm{Ph}+\mathrm{CML}$ according to period of diagnosis. (B) Relative survival of patients with Ph + CML aged 0-64 years according to period of diagnosis.

in $1980-1986$ to $67.5 \%$ [53.6-84.9] and $40.1 \%$ [26.9-59.9] in $1987-1999$ and $82.9 \%$ [74.5-92.3] and $73.7 \%$ [62.6-86.8] in 2000-2009.

Among patients diagnosed in 2000-2009, the 5-year RS rate of patients with CML-NOS $(n=106)$ was 63.6 [46.6-86.8] and the 3-year RS rate of patients with Ph- CML $(n=33)$ was 12.0 [3.9-36.8]. RS curves for the overall cohort are shown in Figure 2 according to the ICD-O- 3 code and period of diagnosis.

\section{Acute transformation}

Data on transformation to acute leukemia were available for 424 patients. The rate of acute transformation fell from $51.8 \%$ among patients diagnosed in $1980-1986$ to $33.5 \%$ in 1987-1999 and only 7.4\% in 2000-2009 $(p<0.0001)$. Acute transformation was less frequent in women than in men ( $19.1 \%$ vs. $28.4 \%, p=0.028$ ), and more frequent in patients with $\mathrm{Ph}-\mathrm{CML}$ than in the rest of the cohort (53.3\% vs. $23.2 \%$, $p=0.0076)$. 


\section{Discussion}

With 781 cases, this is one of largest French multicenter cohorts of patients with CML. Our analysis of data from various geographic and socioeconomic areas provides original information on patients with CML in France.

Median age at diagnosis of $\mathrm{Ph}+\mathrm{CML}$ was 55.8 years, and $33.6 \%$ of patients were aged 65 years or more. The ESR was $0.97[0.88-1.05]$ and the WSR was 0.78 [0.71-0.85]. These results are similar to those reported in northern France (Nord-Pas de Calais), where median age was 56 years, $32 \%$ of patients were 65 years or older and the ESR was 1.3 for men and 0.9 for women [21]. Likewise, a population-based study in south-east England conducted in 1999-2000 showed an ESR of 1.09 and a WSR of 0.83 [22].

Osca-Gelis et al. published similar incidence rates, with an ESR of 0.96 in the province of Girona, Spain, between 1994 and 2008, and a median age of 64 years for men and 60 years for women [23]. The Surveillance of Rare Cancers in Europe (RARECARE) project showed a standardized incidence rate of 1.2 cases (standard error 0.01 ) per 100000 person-years in an analysis of 64 European population-based cancer registries of patients diagnosed from 1995 to 2002 [24]. The Côte-d'Or specialized registry of hematologic malignancies, which was included in our study, has published a CML WSR of 0.9 (1.1 for men and 0.7 for women) [25]. Crude and standardized incidence rates based on published registry data are shown in Table IV. Recently, the HAEMACARE project, designed to improve the standardization and availability of population-based data on hematologic malignancies archived by EUROCARE cancer registries, published incidence rates of hematologic malignancies in Europe for the period 2000-2002 [26], using data from 44 cancer registries operating in 20 countries. The Côte-d'Or registry was the only French registry specializing in hematologic malignancies to participate in this study. Cases of CML with ICD-O-3 codes 9863/3 and 9875/3 were included. With 2468 cases, the crude incidence rate was 1.10 [1.06-1.15] per 100000 person-years
(1.23 [1.17-1.30] for men and 0.98 [0.92-1.04] for women), and the incidence of CML increased with age: the incidence was higher at age 75 years or more than between 65 and 74 years. These rates are higher than in our cohort, in which the incidence among patients aged 75 years or more tended to decrease (2.58 vs. 2.24 per 100000 person-years), except in the Doubs registry in which it increased. This result is difficult to explain, but might be due to under-diagnosis among older patients, particularly in rural France.

The RS rate improved between 1980-1986 and 1987-1999 when IFN $\alpha$ was the main therapy, and more significantly after 2000, when TKIs showed efficacy in the general population of patients with $\mathrm{Ph}+\mathrm{CML}$. Estimates of net survival among patients with CML in France between 1989 and 2004, including patients included in the FRANCIM network of cancer registries, showed that the net 5-year age-standardized survival rate increased from $47 \%$ to $69 \%$ for patients diagnosed between 2001 and 2004, corresponding to the advent of TKIs [27]. Efficacy was higher in patients younger than 75 years. In the IRIS study, which compared first-line IM versus IFN $\alpha$ and cytarabine, the 5-year overall survival rate estimated for selected patients aged 18-70 years in the chronic phase was $89 \%$ [86-92] [28]. In this trial, a large proportion of patients in the IFN $\alpha$ and cytarabine arm crossed over to the IM arm. The M. D. Anderson Cancer Center CML database shows an 8 -year survival rate of $87 \%$ since 2001 [29]. In our populationbased study, we found that RS improved in each age category, including $\geq 65$ years. Osca-Gelis et al. published a 5-year RS of 61 months for patients diagnosed in 1994-2008 in Girona, Spain among a heterogeneous population: 43 patients of 99 received TKIs [30]. They performed a multivariate analysis of relative excess risk (RER) of death adjusted for TKI treatment, gender and age. The RER was statistically significantly inferior for patients treated with TKIs $(\mathrm{RER}=0.19$ [0.06-0.60], $p<0.001$ ). In our cohort, long-term survivors ( $4 \%$ of patients diagnosed in 1980-1986, $29 \%$ of patients diagnosed in 19871999) received TKIs after 2000 . We chose not to compare patients according to TKI treatment, because of a survival

Table IV. Crude and standardized incidence ratio stemming from registries data.

\begin{tabular}{|c|c|c|c|c|c|c|c|c|c|}
\hline Registries & & & Period & $\begin{array}{c}\text { Crude } \\
\text { incidence }\end{array}$ & $95 \% \mathrm{CI}$ & ESR & $95 \% \mathrm{CI}$ & WSR & $95 \% \mathrm{CI}$ \\
\hline South-East England & CML & Men & $1999-2000$ & 2.06 & - & 1.34 & - & 1.00 & - \\
\hline \multirow[t]{2}{*}{ Phekoo KJ. et al. 2006} & & Women & & 1.39 & - & 0.87 & - & 0.67 & - \\
\hline & & All & & & - & 1.09 & - & 0.83 & - \\
\hline HAEMACARE & $\mathrm{Ph}+$ _CML \& CML_NOS & Men & 2000-2002 & 1.23 & [1.17-1.30] & - & - & - & - \\
\hline \multirow[t]{2}{*}{ Sant M. et al. 2010} & & Women & & 0.98 & {$[0.92-1.04]$} & - & - & - & - \\
\hline & & All & & 1.10 & [1.06-1.50] & - & - & - & - \\
\hline Nord-Pas de Calais & $\mathrm{Ph}+$ CML & Men & 1990-2007 & - & - & 1.3 & - & 1.00 & - \\
\hline Corm S. et al. 2011 & & Women & & - & - & 0.9 & - & 0.70 & - \\
\hline RARECARE & $\mathrm{Ph}+$ CML \& CML_NOS & Men & 1995-2002 & 1.40 & - & - & - & - & - \\
\hline \multirow[t]{2}{*}{ Visser et al. 2012} & & Women & & 1.10 & - & - & - & - & - \\
\hline & & All & & 1.20 & - & - & - & - & - \\
\hline Girona, Spain & CML & Men & 1994-2008 & - & - & 1.13 & - & - & - \\
\hline \multirow[t]{2}{*}{ Osca-Gelis G. et al. 2013} & & Women & & - & - & 0.82 & - & - & - \\
\hline & & All & & 1.15 & - & 0.96 & - & - & - \\
\hline \multirow[t]{6}{*}{ Our cohort } & $\mathrm{Ph}+$ CML & Men & 1990-2009 & 1.24 & - & 1.12 & [0.99-1.24] & 1.09 & {$[0.96-1.22]$} \\
\hline & & Women & & 0.91 & - & 0.85 & {$[0.74-0.95]$} & 0.74 & {$[0.63-0.84]$} \\
\hline & & All & & 1.07 & - & 0.97 & {$[0.88-1.05]$} & 0.78 & {$[0.71-0.85]$} \\
\hline & $\mathrm{Ph}+$ CML \& CML_NOS & Men & & 1.41 & - & 1.27 & {$[1.14-1.41]$} & 1.25 & [1.11-1.39] \\
\hline & & Women & & 1.07 & - & 0.96 & {$[0.86-1.08]$} & 0.83 & {$[0.72-0.93]$} \\
\hline & & All & & 1.24 & - & 1.10 & [1.01-1.19] & 0.89 & {$[0.81-0.96]$} \\
\hline
\end{tabular}

Ph+_CML, Philadelphia chromosome-positive chronic myeloid leukemia; CML_NOS: chronic myeloid leukemia not otherwise specified; CI, confidence interval. 
bias for patients for patients diagnosed before 2000: indeed only long-term survivors could be treated with TKIs during follow-up.

The difference in survival between patients diagnosed in 1987-1999 and 2000-2009 was significant for all age classes, contrary to the results of the Surveillance, Epidemiology and End Results Program of the United States National Cancer Institute [31], which showed a significant improvement in the 5- and 10-year RS rates in all age categories except for $65-74$ and $\geq 75$ years. Five-year RS rates among patients with $\mathrm{Ph}+\mathrm{CML}$ are shown in Table $\mathrm{V}$ for different populationbased studies and calendar periods.

In an Italian study, cumulative complete cytogenetic and molecular remission rates were the same in patients aged 65 years or more as in younger patients [32]. Most of the patients aged 65 years or more who died during follow-up were in complete hematologic remission, suggesting more severe treatment-related toxicity in this age range. A large Swedish population-based study [33] of RS among patients with CML according to the calendar period of diagnosis showed a significant improvement in the estimated 5-year RS rate for all age categories from 1973-1979 to 2001-2008, but the increase between 1994-2000 and 2001-2008 among patients aged 79 or more was smaller than in other age categories, despite a large increase among patients aged 70-79 years. As in an American study [34], we found disparities in access to TKIs between patients aged 75 years or more and younger patients $(p=0.0008)$. It is possible that prescribing physicians believe that older patients are more likely to experience adverse effects of TKIs (fatigue, musculoskeletal disorders), but this is not supported by published data. On the contrary, younger patients and women may be more susceptible to these adverse effects [35].

CML patient survival in the TKI era remains poorer than that of the general population of the same age and gender. This could be explained by the occurrence of blast crisis before an optimal therapeutic response is achieved, and also by the onset of mutations conferring resistance to IM [36]. Second-generation TKIs may reduce mortality related to these factors. Epidemiological studies have shown that some second malignancies occur during TKI therapy, but no causative relationship has been found [37,38]. A

Table V. Relative 5-year suvival of $\mathrm{Ph}+$ _CML patients according population-based studies and period.

\begin{tabular}{|c|c|c|c|c|}
\hline Article & $n$ & Period & $\begin{array}{c}\text { Relative } \\
5 \text {-year } \\
\text { survival (\%) }\end{array}$ & $95 \%$ CI \\
\hline SEER & 8329 & $1990-1992$ & 21.1 & - \\
\hline $\begin{array}{l}\text { Brenner H. et al. } \\
2008\end{array}$ & & $2002-2004$ & 48.7 & - \\
\hline Sweden & 3173 & $1973-1979$ & 21 & {$[17-24]$} \\
\hline \multirow[t]{2}{*}{$\begin{array}{l}\text { Björkholm M. et al. } \\
2011\end{array}$} & & $1994-2000$ & 54 & {$[50-58]$} \\
\hline & & 2001-2008 & 80 & [75-83] \\
\hline Nord-Pas de Calais & 691 & 1990-1994 & 64 & {$[56-71]$} \\
\hline \multirow[t]{2}{*}{ Corm S. et al. 2011} & & 1995-1999 & 66 & {$[57-76]$} \\
\hline & & $2000-2007$ & 88 & {$[80-93]$} \\
\hline \multirow[t]{3}{*}{ Our cohort } & 642 & $1980-1986$ & 43.7 & [30.9-61.9] \\
\hline & & 1987-1999 & 63.8 & {$[56.9-71.5]$} \\
\hline & & $2000-2009$ & 88.7 & {$[84.5-89.4]$} \\
\hline
\end{tabular}

CI: confidence interval. population-based study conducted before the TKI era showed significantly higher standardized incidence ratios (SIRs) for stomach cancer ( $\mathrm{SIR}=2.76,95 \% \mathrm{CI}$ : 1.33-5.08), urogenital cancers ( $\mathrm{SIR}=1.61,95 \% \mathrm{CI}$ : 1.15-2.21) and skin cancer $(\mathrm{SIR}=5.36,95 \% \mathrm{CI}: 3.18-8.47)$ in patients with $\mathrm{CML}$ compared to the general population [39].

Our survival results are coherent with trends in CML mortality reported after IM introduction in Japan and the USA [40]. In our cohort, patients diagnosed as 9876/3 (Ph - CML) had a higher mean age than the overall cohort (71.8 vs. 56.7 years, $p<0.0001$ ), and also experienced more acute transformations and a lower survival rate. These patients, formerly classified as having atypical CML (aCML), were reclassified as having unclassifiable myelodysplastic/myeloproliferative syndromes (MDS/MPS) in the 2008 World Health Organization (WHO) "classification of tumors of hematopoietic and lymphoid tissues" [41]. aCML is characterized by splenomegaly and neutrophilic leukocytosis associated with dysgranulopoiesis and circulating immature granulocytes. In a retrospective study from the M. D. Anderson Cancer Center [42], the median overall survival time of these patients was 24 months. In our cohort it was less 20 months, and did not differ across the three study periods. Except for BMT, there is no effective therapeutic option for these patients. Among patients diagnosed as 9876/3 in 2000-2009, 29.4\% received a TKI with no improvement in survival, confirming the heterogeneity of the pathological mechanism. Code 9876/3 should be removed from future versions of the ICD-O.

Patients classified as CML-NOS have no available cytogenetic or molecular analyses and probably form a heterogeneous group. This lack of information on BCR-ABL status may be related to the presence of adverse clinical prognostic factors, in elderly patients for example. Nevertheless, some of these patients benefited from TKI therapy, as the 8-year survival rate was higher among patients diagnosed in 2000-2009 than in those diagnosed in 1987-1999, in whom TKIs were used in respectively $93.3 \%$ and $29.4 \%$ of cases $(p=0.0003)$. Currently, the proportion of CML-NOS is rather low, probably due to better access to appropriate genetic and molecular analyses for diagnosis.

As cytogenetic aberrations at diagnosis [trisomy 8, second $\mathrm{Ph}$ chromosome and isochromosome (17)(q10)] may have an important impact on the prognosis of CML (the 5-year survival rate is only $53 \%$ despite treatment with IM [43]), exhaustive recording of cytogenetic aberrations in registries might prove useful. The complexity of classification and recording of pertinent information in hematologic malignancies underlines the need for specialized registries. RS rates for patients diagnosed during the last decade suggests a margin of possible progression for observance improvement and for new drugs based on molecular targeting.

\section{Conclusion}

During the last 30 years, major therapeutic advances have led to a significant improvement in the RS of patients with CML. For example, the 5-year RS rates among patients with $\mathrm{Ph}+\mathrm{CML}$ were 43.7\% [30.9-61.9] when diagnosed in $1980-1986,63.8 \%$ [56.9-71.5] in 1987-1999 and $88.7 \%$ 
[84.5-93.0] in 2000-2009. The 8-year RS rate of patients with $\mathrm{Ph}+\mathrm{CML}$ diagnosed in 2000-2009 was 83.3\% [77.5-89.4]. TKIs have thus dramatically improved the prognosis of all patients with $\mathrm{Ph}+\mathrm{CML}$, not only those included in clinical trials.

Potential conflict of interest: Disclosure forms provided by the authors are available with the full text of this article at www.informahealthcare.com/lal.

\section{References}

[1] Nowell PC. The minute chromosome (Phl) in chronic granulocytic leukemia. Blut 1962;8:65-66.

[2] Arkesteijn GJ, Martens AC, Hagenbeek A. Bivariate flow karyotyping in human Philadelphia-positive chronic myelocytic leukemia. Blood 1988;72:282-286.

[3] VerschraegenCF, TalpazM, Hirsch-GinsbergCF, etal. Quantification of the breakpoint cluster region rearrangement for clinical monitoring in Philadelphia chromosome-positive chronic myeloid leukemia. Blood 1995;85:2705-2710.

[4] Interferon alfa versus chemotherapy for chronic myeloid leukemia: a meta-analysis of seven randomized trials: Chronic Myeloid Leukemia Trialists' Collaborative Group. J Natl Cancer Inst 1997;89:1616-1620.

[5] Clift R, Appelbaum F, Thomas E. Treatment of chronic myeloid leukemia by marrow transplantation. Blood 1993;82:1954-1956.

[6] Moreb J, Johnson T, Kubilis P, et al. Improved survival of patients with chronic myelogenous leukemia undergoing allogeneic bone marrow transplantation. Am J Hematol 1995;50:304-306.

[7] Druker B. Signal transduction inhibition: results from phase I clinical trials in chronic myeloid leukemia. Semin Hematol 2001; 38:9-14.

[8] O'Brien SG, Guilhot F, Larson RA, et al. Imatinib compared with interferon and low-dose cytarabine for newly diagnosed chronic-phase chronic myeloid leukemia. N Engl J Med 2003;348:994-1004.

[9] Kantarjian HM, O'Brien S, Cortes J, et al. Imatinib mesylate therapy improves survival in patients with newly diagnosed Philadelphia chromosome囚positive chronic myelogenous leukemia in the chronic phase. Cancer 2003;98:2636-2642.

[10] Jabbour E, Cortes J, Kantarjian H. Nilotinib for the treatment of chronic myeloid leukemia: an evidence-based review. Core Evid 2010;4:207-213.

[11] Kantarjian H, Shah NP, Hochhaus A, et al. Dasatinib versus imatinib in newly diagnosed chronic-phase chronic myeloid leukemia. N Engl J Med 2010;362:2260-2270.

[12] Giles FJ, Rosti G, Beris P, et al. Nilotinib is superior to imatinib as first-line therapy of chronic myeloid leukemia: the ENESTnd study. Expert Rev Hematol 2010;3:665-673.

[13] Percy C, Van Holten V, Muir C. International Classification of Diseases for Oncology. 2nd ed. Geneva: World Health Organization; 1990.

[14] Fritz A, Percy C, Jack A, et al. International Classification of Diseases for Oncology. 3rd ed. Geneva: World Health Organization; 2000.

[15] Bouyer J, Hémon D, Cordier S, et al. Epidémiologie - principes et méthodes quantitatives. Paris: Éditions Inserm; 1993.

[16] Estimation de la population au ler janvier par région (1990-2010), département (1990-2009), sexe et âge (quinquennal, classes d'âge). Paris: Institut national de la statistique et des études économiques; 2012. Available from: www.insee.fr/fr/themes/detail.asp?ref_id $=\mathrm{e}$ stim-pop\&reg_id $=99$

[17] Waterhouse J., Correa P, Muir C, et al., editors. Cancer incidence in five continents, Vol. III. Lyon: IARC; 1976.

[18] Segi M. Cancer mortality for selected sites in 24 countries (1950-57). Department of Public Health, Tohoku University of Medicine, Sendai, Japan. 1960.

[19] Human Mortality Database. University of California, Berkeley (USA), and Max Planck Institute for Demographic Research (Germany). Available from: www.mortality.org; www.humanmortality.de

[20] Pohar M, Stare J. Relative survival analysis in R. Comput Methods Programs Biomed 2006;81:272-278.

[21] Corm S, Roche L, Micol J-B, et al. Changes in the dynamics of the excess mortality rate in chronic phase-chronic myeloid leukemia over 1990-2007: a population study. Blood 2011;118:4331-4337.
[22] Phekoo KJ, Richards MA, Møller $\mathrm{H}$, et al. The incidence and outcome of myeloid malignancies in 2,112 adult patients in southeast England. Haematologica 2006;91:1400-1404.

[23] Osca-Gelis G, Puig-Vives M, Saez M, et al. Populationbased incidence of myeloid malignancies: fifteen years of epidemiological data in the province of Girona, Spain. Haematologica 2013;98:e95-e97.

[24] Visser O, Trama A, Maynadié $M$, et al. Incidence, survival and prevalence of myeloid malignancies in Europe. Eur J Cancer 2012;48:3257-3266.

[25] Maynadié M, Girodon F, Manivet-Janoray I, et al. Twenty-five years of epidemiological recording on myeloid malignancies: data from the specialized registry of hematologic malignancies of Côte d'Or (Burgundy, France). Haematologica 2011;96:55-61.

[26] Sant M, Allemani C, Tereanu C, et al. Incidence of hematologic malignancies in Europe by morphologic subtype: results of the HAEMACARE project. Blood 2010;116:3724-3734.

[27] Monnereau A, Troussard X, Belot A, et al. Unbiased estimates of long-term net survival of hematological malignancy patients detailed by major subtypes in France. Int J Cancer 2013;132:2378-2387.

[28] Druker BJ, Guilhot F, O'Brien SG, et al. Five-year follow-up of patients receiving imatinib for chronic myeloid leukemia. N Engl J Med 2006;355:2408-2417.

[29] Kantarjian H, O'Brien S, Jabbour E, et al. Improved survival in chronic myeloid leukemia since the introduction of imatinib therapy: a single-institution historical experience. Blood 2012;119: 1981-1987.

[30] Osca-Gelis G, Puig-Vives M, Saez M, et al. Is survival in myeloid malignancies really improving? A retrospective 15 -year populationbased study. Leuk Lymphoma 2014 Aug 18. [Epub ahead of print]

[31] Brenner H, Gondos A, Pulte D. Recent trends in long-term survival of patients with chronic myelocytic leukemia: disclosing the impact of advances in therapy on the population level. Haematologica 2008;93:1544-1549.

[32] Gugliotta G, Castagnetti F, Palandri F, et al. Frontline imatinib treatment of chronic myeloid leukemia: no impact of age on outcome, a survey by the GIMEMA CML Working Party. Blood 2011; 117:5591-5599.

[33] Björkholm M, Ohm L, Eloranta S, et al. Success story of targeted therapy in chronic myeloid leukemia: a population-based study of patients diagnosed in Sweden from 1973 to 2008. J Clin Oncol 2011;29:2514-2520.

[34] Wiggins CL, Harlan LC, Nelson HE, et al. Age disparity in the dissemination of imatinib for treating chronic myeloid leukemia. Am J Med 2010;123:764.e1-9.

[35] Efficace F, Baccarani M, Breccia M, et al. Health-related quality of life in chronic myeloid leukemia patients receiving long-term therapy with imatinib compared with the general population. Blood 2011;118:4554-4560.

[36] Yeung DT, Hughes TP. Therapeutic targeting of BCR-ABL: prognostic markers of response and resistance mechanism in chronic myeloid leukaemia. Crit Rev Oncog 2012;17:17-30.

[37] Verma D, Kantarjian H, Strom SS, et al. Malignancies occurring during therapy with tyrosine kinase inhibitors (TKIs) for chronic myeloid leukemia (CML) and other hematologic malignancies. Blood 2011;118:4353-4358.

[38] Voglova J, MuzikJ, Faber E, et al. Incidence of second malignancies during treatment of chronic myeloid leukemia with tyrosine kinase inhibitors in the Czech Republic and Slovakia. Neoplasma 2011; 58:256-262.

[39] Rebora P, Czene K, Antolini L, et al. Are chronic myeloid leukemia patients more at risk for second malignancies? A population-based study. Am J Epidemiol 2010;172:1028-1033.

[40] Chihara D, Ito $\mathrm{H}$, Matsuda $\mathrm{T}$, et al. Decreasing trend in mortality of chronic myelogenous leukemia patients after introduction of imatinib in Japan and the U.S. Oncologist 2012;17:1547-1550.

[41] Vardiman JW, Thiele J, Arber DA, et al. The 2008 revision of the World Health Organization (WHO) classification of myeloid neoplasms and acute leukemia: rationale and important changes. Blood 2009;114:937-951.

[42] Onida F, Ball G, Kantarjian HM, et al. Characteristics and outcome of patients with Philadelphia chromosome negative, bcr/abl negative chronic myelogenous leukemia. Cancer 2002;95: 1673-1684.

[43] Fabarius A, Leitner A, Hochhaus A, et al. Impact of additional cytogenetic aberrations at diagnosis on prognosis of CML: long-term observation of 1151 patients from the randomized CML study IV. Blood 2011;118:6760-6768. 